\title{
Comparison of Galdieria growth and photosynthetic activity in different culture systems
}

Dora Allegra Carbone ${ }^{1 *}$, Giuseppe Olivieri ${ }^{2,3}$, Antonino Pollio ${ }^{4}$ and Michael Melkoniann 5,6

\begin{abstract}
In the last years, the acidothermophilic red microalga Galdieria sulphuraria has been increasingly studied for industrial applications such as wastewater treatment, recovery of rare earth elements, production of phycobilins. However, even now it is not possible an industrial cultivation of this organism because biotechnological research on G. sulphuraria and allied species is relatively recent and fragmented. Having in mind a possible scale-up for commercial applications, we have compared the growth and photosynthetic performance of G. sulphuraria in four suspended systems (Inclined bubble column, Decanter Laboratory Flask, Tubular Bioreactor, Ultra-flat plate bioreactor) and one immobilized system (Twin Layer Sytem). The results showed that G. sulphuraria had the highest growth, productivity and photosynthetic performance, when grown on the immobilized system, which also offers some economics advantages.
\end{abstract}

Keywords: Galdieria sulphuraria, photobioreactors, biomass, comparison

\section{Keypoints}

Comparison of different microalgal cultivation systems (suspended and immobilized)

Analysis of growth and photosynthetic performance Immobilized cultivation on the Twin layer system showed the best performance with respect to growth and photosynthesis

\section{Introduction}

Cyanidiophyceae are a class of red microalgae living in extreme environments (Albertano et al. 2000; Pinto et al. 2003; Yoon et al. 2004). They prevalently thrive in geothermal volcanic areas at temperatures around $40{ }^{\circ} \mathrm{C}$ and at high sulfuric acid concentrations, with ambient $\mathrm{pH}$ values between 1 and 3 (Albertano et al. 2000; Pinto et al.

\footnotetext{
*Correspondence: doraallegra.carbone@szn.it

1 Laboratory of Biological Oceanography, Stazione Zoologica "A. Dohrn" of Napoli, Villa Comunale, Napoli I80121, Italy

Full list of author information is available at the end of the article
}

2007; Toplin et al.2008; Castenholz and Mcdermott 2010; Ciniglia et al. 2014; Ciniglia et al. 2017)

These extreme environmental conditions strongly limit contaminations that are prevalent in open microalgal mass cultivation systems. In consequence, these organisms are of considerable interest for commercial applications (Carfagna et al. 2018; Carbone et al. 2019).

Cyanidiophyceae are divided into three genera, Cyanidium, Galdieria, and Cyanidioschyzon (Gross 2000; Heilmann and Gross 2001; Ciniglia et al. 2004; Del Mondo et al.2019) but only Galdieria is known to grow heterotrophically, also achieving a higher biomass density (Gross et al. 1998; Gross and Schnarrenberger 1995; Graziani et al. 2013, Vítová et al. 2016); therefore it is considered a promising candidate for industrial applications.

Indeed, Galdieria has been the subject of different studies in algal biotechnology. It was used for wastewater treatment (Ju et al. 2016; Henkanette-Gedera et al. 2016; da Silva et al. 2016; Carbone et al. 2018; Galasso et al. 2019; Alalwan et al. 2019; Sosa-Hernández et al. 2019) and for recovery of rare earth elements (Minoda et al. 2015). Moreover, this organism produces high levels of phycobiliproteins that are used in diverse medical and
Springer Open (c) The Author(s) 2020. This article is licensed under a Creative Commons Attribution 4.0 International License, which permits use, sharing, adaptation, distribution and reproduction in any medium or format, as long as you give appropriate credit to the original author(s) and the source, provide a link to the Creative Commons licence, and indicate if changes were made. The images or other third party material in this article are included in the article's Creative Commons licence, unless indicated otherwise in a credit line to the material. If material is not included in the article's Creative Commons licence and your intended use is not permitted by statutory regulation or exceeds the permitted use, you will need to obtain permission directly from the copyright holder. To view a copy of this licence, visit http://creativeco mmons.org/licenses/by/4.0/. 
cosmetic products (Schmidt et al. 2005; Graverholt and Eriksen 2007; Sørensen et al. 2013; Eriksen 2018) and in different compounds with antioxidant properties (Carfagna et al. 2016).

However, biotechnological research on Galdiera is relatively recent. The data around the growth of this microalga are still fragmentary and even now it is not possible an industrial cultivation of this organism.

Therefore, having in mind a possible scale-up and commercial applications of G. sulphuraria, in this paper, the growth and the photosynthetic performance of this microalga were systematically compared in five different types of cultivation systems (one immobilized and four suspended) at the same conditions of temperature and irradiance.

\section{Materials and methods}

\section{Algal strain and stock cultures}

Galdieria sulphuraria strain 064 from ACUF collection (D'elia et al. 2018 http://www.acuf.net) was chosen. The stock culture was cultivated in Galdieria medium (Gross and Schnarrenberger 1995) acidified by sulfuric acid at $\mathrm{pH}$ 1.5. Stock cultures were grown in 11 Erlenmeyer flasks and were exposed to an adaptive light intensity of $30 \mu \mathrm{mol}$ photons $\mathrm{m}^{-2} \mathrm{~s}^{-1}$ with a light/dark cycle of $14 / 10 \mathrm{~h}$. The temperature was $35^{\circ} \mathrm{C}$.

\section{Analysis of growth}

We consider several parameters to analyse growth. These parameters are depending variables of time, the only independent variable. Some depending variables, denoted with the term "specific", are normalized by dividing by the initial values, to take the different inocula into account (conversely, the non-normalized depending variables can be obtained multiplying the normalized ones by the initial values). We explicitly observe that normalization is necessary because Twin-Layer S needs inocula concentrations very different from those used for suspended systems.

The considered variables are: coefficient of determination, specific weight increase, specific light yield, growth rate.

\section{Coefficient of determination}

The coefficient of determination $\left(\mathrm{r}^{2}\right)$ is a measure of how close the data are to the regression line. It was used to compare the different bioreactor systems.

\section{Specific weight increase (SWI)}

The specific weight increase (SWI) was used to analyse the trend of growth in the different bioreactors.

This is the formula defining SWI:

$$
S W I(t)=\frac{w(t)-w(0)}{w(0)}
$$

where $w(t)$ is the dry weight at day $t$ (more exactly, $t$ is the number of the day when the sampling is taken and measured) and $w(0)$ the dry weight at day $0(\mathrm{~g})$.

\section{Specific light yield (SLY)}

To consider the light energy necessary for the growth, we used the standard light yield and normalized it. The formula for the specific light yield (SLY) (photons $\mathrm{mol}^{-1}$ ) is the following:

$$
S L Y(t)=\frac{S W I(t)}{A * t * s * p m}
$$

where $S W I(x)$ is the specific weight increase, $A$ the area of surface of the bioreactor exposed to the light $\left(\mathrm{m}^{2}\right), t$ is the number of days, $s$ is the number of seconds of illumination per day (s) (in our case, this number, 50,400, is obtained multiplying the number of illuminations hours, 14 , by the number of seconds in a hour, 3600), pm is the number of the given moles of photosynthetically active photons per second and per square meter (photons mol $\mathrm{s}^{-1} \mathrm{~m}^{-2}$ ) (in our case, $p m$ is the number of the given PAR, 100 , multiplied by $10^{-6}$ ).

\section{Growth rate (GR)}

The growth rate in the time period is calculated thanks to the growth rate GR $\left(\right.$ day $\left.^{-1}\right)$ with this formula:

$$
G R(t)=\frac{\operatorname{Ln} \frac{w(t+h)}{w(t)}}{h}
$$

where $\operatorname{Ln}$ is the natural logarithm, $w(t+h)$ is the dry weight at day $t+h, w(\mathrm{t})$ is the dry weight at day $t, h$ is the number of days between two consecutive measures (in our case, $h$ is equal to 3 ).

\section{Determination of biomass}

In liquid cultivation systems, $2 \mathrm{ml}$ of the culture was harvested every three days in triplicate with a sterile syringe for dry mass determinations and then filtered on a polycarbonate disc using a vacuum pump. In Twin Layer System, the polycarbonate discs were taken off from the bioreactor and biomass in the inoculated area was considered, while the rest was scraped off.

All samples were lyophilized in a freeze dryer for two hours and weighed with an analytical balance (Sartorius Bovenden, Germany). 


\section{Analysis of the photosynthetic state of microalgae}

Pigment concentration: microalgae were harvested and lyophilised then they were mixed with quartz sand to obtain homogeneous powder.

Photosynthetic pigments were extracted overnight with acetone (Costache et al. 2012). Chlorophyll a and carotenoids were analysed by spectrophotometry (Shimadzu UV-2450) (Tomitani et al. 1999).

\section{Pigment concentration}

Different formulae were considered to compare the photosynthetic state of each culture.

These equations were used:

$$
\begin{aligned}
& \text { Chl } a=11.75 *(A 662)-2.350 *(\text { A645 }) \\
& \text { Carotenoids }=\frac{1000 *(A 470)-(2.270 C h l a)}{227}
\end{aligned}
$$

where Chl $a$ is the concentration of chlorophyll a (mg $\left.1^{-1}\right)$, Carotenoids is the concentration of total carotenoids $\left(\mathrm{mg} \mathrm{l}^{-1}\right)$, and $\mathrm{A}$ is the absorbance at different wavelengths $(662,645,470 \mathrm{~nm})$ (Costache et al. 2012).

\section{Specific pigments increase}

The trend of pigment concentration during growth tests was calculated according to the formula:

$$
S P(t)=\frac{p(t)-p(0)}{p(0)}
$$

where $p(t)$ is the concentration of the pigment (chlorophyll or carotenoids) at time $\mathrm{t}\left(\mathrm{mg} \mathrm{ml}^{-1}\right.$ for liquid systems and $\mathrm{g} \mathrm{m}^{-2}$ for Twin Layer System) and $\mathrm{p}(0)$ is the concentration of the pigment at time $0\left(\mathrm{mg} \mathrm{ml}^{-1}\right.$ for liquid systems and $\mathrm{g} \mathrm{m}^{-2}$ for Twin Layer System), obtained by the previous formulae.

\section{Normalized photosynthesis efficiency (NPE)}

NPE is the efficiency of solar light energy captured and stored in biomass. Therefore it is used to estimate the productivity. We normalized the standard formula for photosynthetic efficiency (De Vree et al. 2015) by using the dry weight at time 0 . The formula for NPE $\left(\mathrm{g}^{-1}\right)$ is the following:

$$
N P E(t)=\frac{\Delta H_{C}^{0} *(w(t+h)-w(t))}{w(0) * h * A * s * p m * N * e}
$$

where $\Delta H_{C}^{0}$ is the standard enthalpy of combustion $(22.5$ $\left.\mathrm{kJ} \mathrm{g}^{-1}\right), w(x+h)$ the biomass dry weight at day $t+h(\mathrm{~g})$, $w(x)$ the biomass dry weight at day $\mathrm{t}(\mathrm{g}), w(0)$ the biomass dry weight at time $0(\mathrm{~g}), h$ the number of days between two consecutive measures (in our case, $h$ is equal to 3 ), $A$ the area of surface of the bioreactor exposed to the light $\left(\mathrm{m}^{2}\right), s$ is the number of seconds of illumination per day (s) (in our case, this number, 50.400, is obtained multiplying the number of illuminations hours, 14, by the number of seconds in a hour, 3.600), pm is the number of the given moles of photosynthetically active photons per second and per square meter (photons mol s${ }^{-1} \mathrm{~m}^{-2}$ ) (in our case, $p m$ is the number of the given PAR, 100, multiplied by $\left.10^{-6}\right), N$ is the Avogadro number, $e$ is the approximate energy of a photon of $400 \mathrm{~nm} 173$ wave length $(\mathrm{kJ})$ (this value is around $4 * 10^{-22}$ ).

In this formula, we normalized by $w(0)$ to highlight the relevant differences between the TL-S system and suspended systems. Moreover, we acknowledge that it can also be significant to normalize by dividing by $\mathrm{w}(\mathrm{t})$ be evidence possible differences between consecutive measurements.

This variable is linked to the productivity of bioreactors and represents the efficiency with which solar energy is captured and stored in biomass (De Vree et al. 2015).

\section{Photobioreactors and bottle design set up}

The experiments were set up at the same light intensity of $100 \mu \mathrm{mol}$ photons $\mathrm{m}^{-2} \mathrm{~s}^{-1}$ with a light/dark cycle of $14 / 10 \mathrm{~h}$ in presence of atmospheric $\mathrm{CO}_{2}$ and at constant temperature of $35{ }^{\circ} \mathrm{C}$. The systems used for the experiments are four suspension systems and one where cells are immobilized on photobioreactor (Fig. 1). In suspension systems the volume of the culture is invariable, because after the sampling of $2 \mathrm{ml}$ water loss was replaced and the growth was influenced only very weakly. At the beginning of the experiment, the culture had an optical density of 0.4 and a dry weight of $0.4 \mathrm{~g} / \mathrm{l}$ while in the Twin Layer System the culture had a dry weight of 20 $\mathrm{g} \mathrm{m}^{-2}$.

- The Twin Layer System (Twin Layer-S) consisted of an immobilized photobioreactor where microalgae are inoculated on a polycarbonate disk that is attached on a hydrophilic substrate by self-adhesion, separating the algal biomass from the bulk of the medium (Nowack et al. 2005; Melkonian and Podola 2010; Li et al. 2017). The algae were placed on the Twin Layer-S only when the liquid culture achieved a sufficient density in suspension (optical density around 0.4 ). Then the algae were harvested by centrifugation for 30 minutes at $2000 \mathrm{rpm}$ (Sorvall, RC5C), filtered onto polycarbonate membranes (PC40, 0.4 $\mu \mathrm{m}$ pore size, $25 \mathrm{~mm}$ diameter, Whatman, Dassel, Germany) and subsequently attached to the hydrophilic substrate (Fig. 1a). This system was chosen because it reproduces the natural habitat of this 


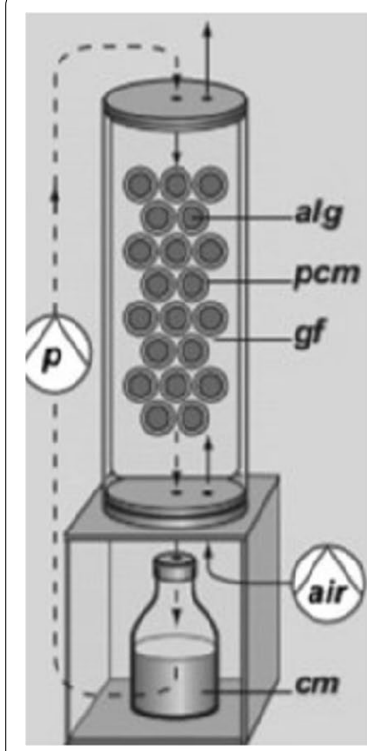

a

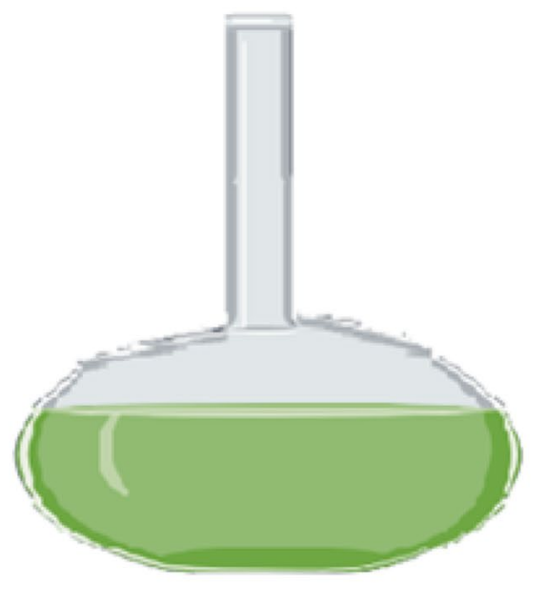

b

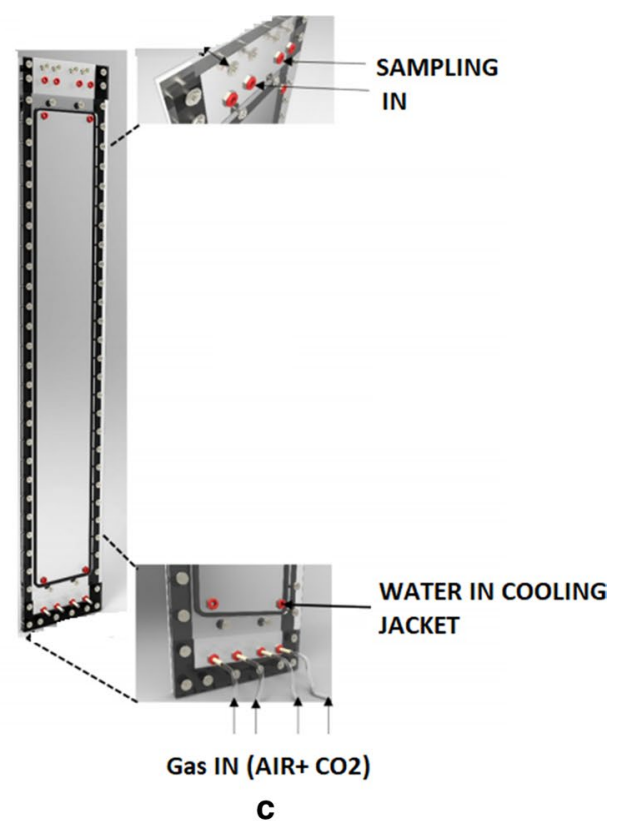

C

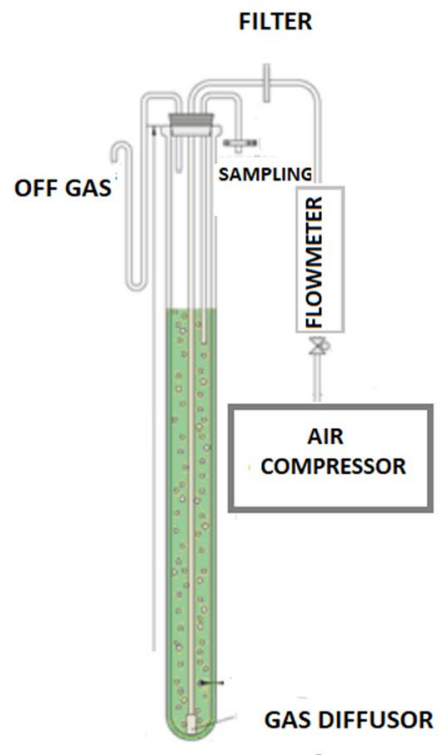

d

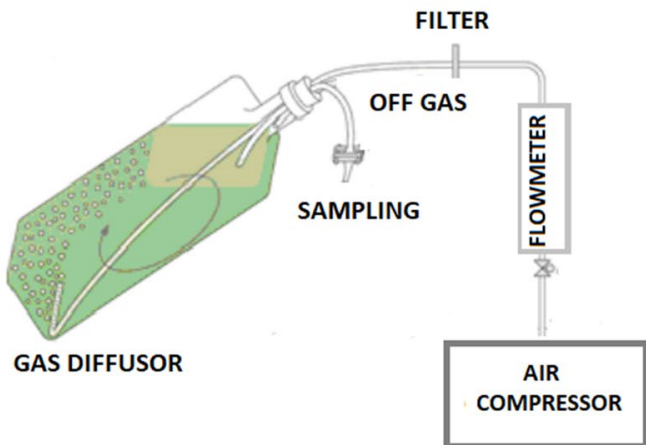

Fig. 1 a Twin-layer system (Twin Layer-S): alg immobilized microalgae, pcm polycarbonate membrane as a carrier for microalgae, gf glass fiber material, air membrane pump for air supply, cm culture medium (figure reproduced and modified from Carbone et al. 2017a, b); b Decanter (Decanter-LF); c A side view of Ultraflate photobioreactor (UP-B) (Gifuni et al. 2018 d Tubular bioreactor (Tubular-B); e Inclined bubble column (Inclined Bubble-C) (Olivieri et al. 2012)

species, generally growing on substrates like soil and rocks (Gross et al. 1998; Ciniglia et al. 2004; Pinto et al. 2007).

- The Decanter laboratory flask (Decanter-LF) had a lighted surface area of $10,201 \mathrm{~cm}^{2}$ and was placed on a platform shaker with at a speed of $50 \mathrm{rpm}$. The total volume of the Decanter-LF was $1000 \mathrm{ml}$ and the working volume was $250 \mathrm{ml}$ (Fig. 1b). The DecanterLF is not a bioreactor and there isn't air flux but it was selected because it is the most common system used in Galdieria growth test (e.g., Iovinella et al. 2020).

- The Ultra-flat plate bioreactor (Flat-UPB) had a lighted surface area of $715 \mathrm{~cm}^{2}$ and was composed of 
three plexiglass panels spaced by two silicone sheets. Four $1 \mathrm{~mm}$ orifices from the bottom of the photobioreactor aerated the system with a gas stream. The total volume was $700 \mathrm{ml}$ and working volume was $400 \mathrm{ml}$ (Fig. 1c). This reactor was chosen because it has a high surface area to volume ratio (Gifuni et al. 2018; Zuccaro et al. 2020).

- The Tubular bioreactor (Tubular-B) was a glass column photobioreactor, with a lighted surface area of $275 \mathrm{~cm}^{2}$ and a glass pipe with a membrane pump equipped with a sterile filter at the bottom of the column aerating the system. The total volume was 350 $\mathrm{ml}$, the working volume was $200 \mathrm{ml}$ (Fig. 1d). This type of system was chosen because mixing of the suspension is optimal (Aslanbay Guler et al. 2019; Carbone et al. 2019; Dupré et al. 2020).

- The Inclined bubble column bioreactor (Inclined Bubble-C) was a prism of 2 litres with a rectangular base and a lighted surface area of $300 \mathrm{~cm}^{2}$. On the bottom of the bioreactor, the gas stream was sparged by multiple orifices of a Teflon tube. The working volume was $400 \mathrm{ml}$ (Fig 1e). This system was chosen because it has a good ratio between the photic and the dark zone and the microalgae are not exposed to an excess of light or darkness (Olivieri et al. 2013).

\section{Results}

\section{Algal growth in different cultivation systems}

During the experiment, G. sulphuraria showed differences in growth in the cultivation systems.

The slowest growth was observed in Decanter-LF where, at the end of the experiment, G. sulphuraria was only at the beginning of the exponential growth phase (Fig. 2; Table 1).

In the Inclined Bubble- $C$, the microalgae achieved the stationary growth phase on day 27 but the growth performance was lower than those observed in the others bioreactors (Fig. 2; Table 1).

Also, the Tubular - B and Flat-UPB achieved the stationary growth phase on the day 27 but showed a different behaviour (Fig. 2; Table 1). Indeed, the flat-UPB showed highest values of SWI compared to the other suspension-based bioreactors (around 6.5), while the SLY values were lower than those in the Tubular-B, in which the maximum value was around $0.752 \mathrm{~mol}^{-1}$ on day 24 (Fig. 2; Table 1). The maximum GR value was similar in the two bioreactors (approximately 140 day $^{-1}$; Table 1 ).

In the Twin Layer-S, the SWY maximum values were similar to those of the Flat-UPB while SLY were significantly higher during the first 21 days of cultivation than the values obtained in the other bioreactors (maximally $1.7 \mathrm{~mol}^{-2}$ on day 6, Fig. 2; Table 1). The values declined only in the last time of the tests when SLY values fell below 1.0 (Fig. 2b). Also, the maximum GR was higher in the Twin Layer-S than in the other bioreactors $(0.222$ day $\left.^{-1}\right)$. Instead, the $\mathrm{r}^{2}$ was the lowest of all photobioreactors (Fig. 3; Table 1).

\section{Photosynthetic activity \\ Characterization of photosynthetic pigments}

The photosynthetic pigments were analysed at the same time as biomass growth. Specifically, chlorophyll a and carotenoids were considered.

As in the case of biomass growth, the Decanter-LF showed the lowest chlorophyll SP levels (Fig. 4a; Table 2). Indeed, the $\operatorname{SP}(x)$ achieved a maximum value of 2 only on the last day of the experiment.

In the Inclined Bubble- $C$, chlorophyll a achieved the maximum SP value on day 30 (around 5.4) where in the Tubular B, the maximum SP value was observed on day 27 (around 7.5 Fig. 4a; Table 2).

Compared to the other suspension-based cultivation systems, the flat-UPB showed the highest $\mathrm{SP}(x)$ level of chlorophyll a (around 10) on day 24, and then decreasing around 9 on day 30 (Fig. 4a; Table 2).

In the Twin Layer-S, the chlorophyll a SP maximum value was on day 21, when it reached a value of 15 (Fig. 4a; Table 2).

In all systems, the chlorophyll a percentage was around $0.6 \%$ of the total weight(Fig. $5 a$ ).

The carotenoids had a different trend from chlorophyll a except for the Decanter-LF, in which SP values were similar to those of chlorophyll a (around 1) but the maximum percentage value was $0.3 \%$ of total weight (Figs. $4 \mathrm{~b}$, 5b; Table 2).

The SP values for carotenoids were higher in the Inclined Bubble-C(14) than in the Tubular-B (9) and consequently also the maximum percentage value was higher in the Inclined Bubble-C $(0.3 \%$ and $0.15 \%$ respectively) (Figs. 4b, 5b; Table 2).

In the Flat-UPB, the percentage maximum value was around $0.3 \%$ (day 27) and the SP values were higher than in the other suspension-based photobioreactors, achieving a maximum value around 28 on the day 27.

In the Twin Layer-S, SP for carotenoids displayed a lower value than that in the Flat-UPB (around 20 on day 30 ) and the percentage maximum value was only $0.1 \%$ (Figs. 4b, 5b; Table 2).

\section{Normalized photosynthesis efficiency (NPE)}

When the normalized photosynthetic efficiency was calculated, the Decanter-LF showed the lowest level of $\operatorname{NPE}(x)$, that never exceeded $0.096 \mathrm{~g}^{-1}$. The Flat-UPB and the Inclined Bubble- $C$ showed a similar maximum level of NPE (0.109 $\mathrm{g}^{-1}$ and $0.094 \mathrm{~g}^{-1}$, respectively). 


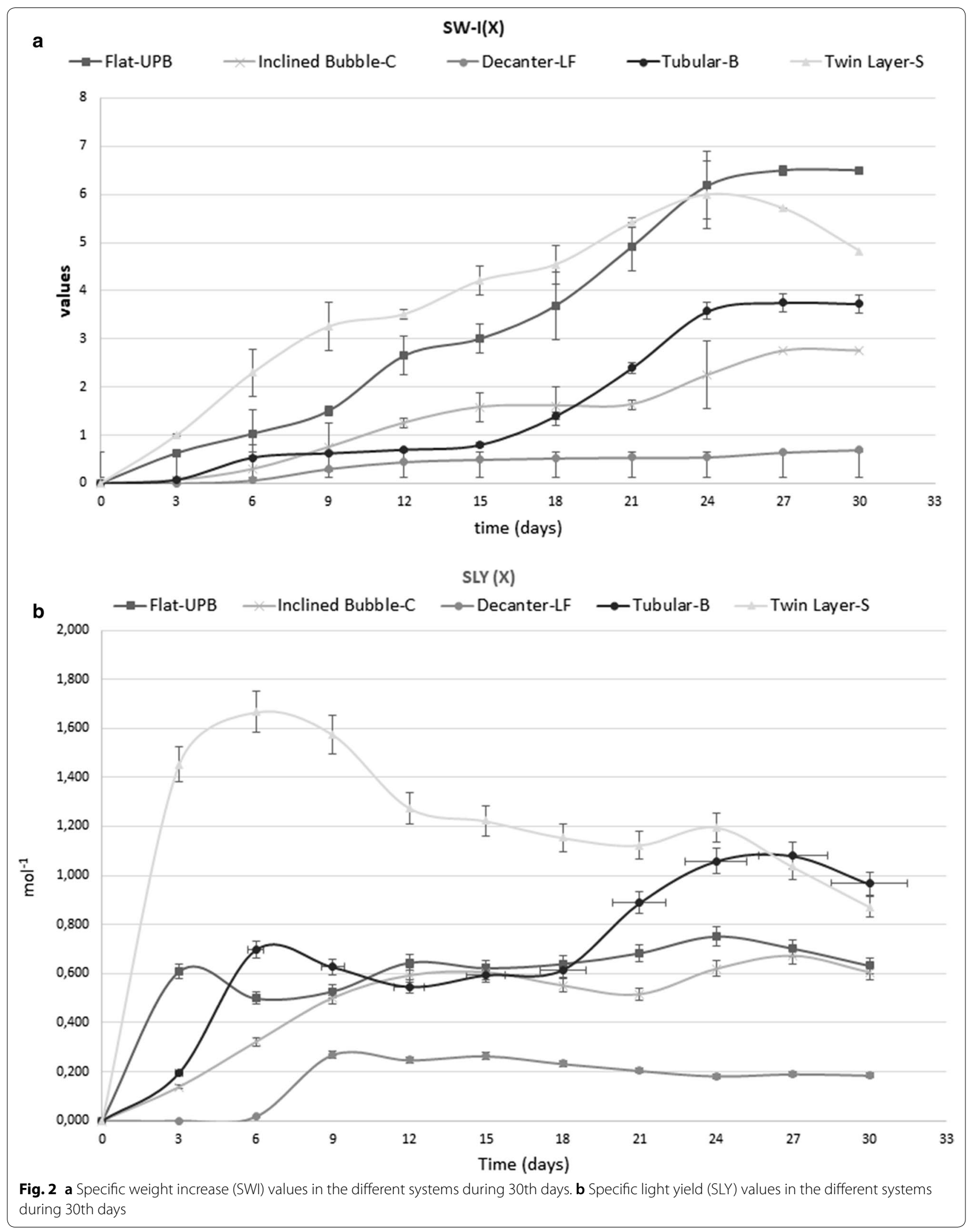


Table 1 Growth parameters of microalgae in different systems

\begin{tabular}{|c|c|c|c|c|c|}
\hline DAYS & $\begin{array}{l}\text { Decanter laboratory flask } \\
\text { (DLF) }\end{array}$ & $\begin{array}{l}\text { Inclined bubble column } \\
\text { (IB-C) }\end{array}$ & $\begin{array}{l}\text { Tubular bioreactor } \\
\text { (T-B) }\end{array}$ & $\begin{array}{l}\text { Ultra-flat plate bioreactor } \\
\text { (UP-B) }\end{array}$ & $\begin{array}{l}\text { Twin layer } \\
\text { system } \\
\text { (TW-S) }\end{array}$ \\
\hline \multicolumn{6}{|c|}{ Specific weight increase (SWI) } \\
\hline 0 & 0 & 0 & 0 & 0 & 0 \\
\hline 3 & 0 & 0.0625 & 0.075 & 0.625 & 1 \\
\hline 6 & 0.0625 & 0.517 & 0.5357 & 1.025 & 2.29 \\
\hline 9 & 0.305 & 0.7 & 0.625 & 1.5 & 3.25 \\
\hline 12 & 0.45 & 0.903 & 0.7 & 2.65 & 3.51 \\
\hline 15 & 0.5 & 1.033 & 0.8 & 3 & 4.2 \\
\hline 18 & 0.52 & 1.044 & 1.4 & 3.69 & 4.84 \\
\hline 21 & 0.541 & 1.0566 & 2.39 & 4.9 & 5.4 \\
\hline 24 & 0.55 & 1.3 & 3.57 & 6.1 & 6.2 \\
\hline 27 & 0.65 & 1.5 & 3.75 & 6.5 & 5.7 \\
\hline 30 & 0.7 & 1.5 & 3.72 & 6.5 & 4.7 \\
\hline \multicolumn{6}{|c|}{ Specific light yield (SLY) Mol ${ }^{-1}$} \\
\hline 0 & 0 & 0 & 0 & 0 & 0 \\
\hline 3 & 0 & 0.137 & 0.194 & 0.608 & 1.4 \\
\hline 6 & 0.017 & 0.321 & 0.697 & 0.498 & 1.66 \\
\hline 9 & 0.269 & 0.501 & 0.626 & 0.527 & 1.57 \\
\hline 12 & 0.248 & 0.593 & 0.546 & 0.644 & 1.27 \\
\hline 15 & 0.265 & 0.606 & 0.593 & 0.622 & 1.22 \\
\hline 18 & 0.233 & 0.551 & 0.615 & 0.639 & 1.15 \\
\hline 21 & 0.205 & 0.516 & 0.887 & 0.683 & 1.12 \\
\hline 24 & 0.185 & 0.620 & 1.05 & 0.752 & 1.19 \\
\hline 27 & 0.191 & 0.670 & 1.08 & 0.702 & 1.03 \\
\hline 30 & 0.181 & 0.606 & 0.966 & 0.632 & 0.87 \\
\hline \multicolumn{6}{|c|}{ Growth rate (GR) day ${ }^{-1}$} \\
\hline 0 & 0 & 0 & 0 & 0 & 0 \\
\hline 3 & 0.020 & 0.020 & 0.024 & 0.140 & 0.221 \\
\hline 6 & 0.068 & 0.06 & 0.119 & 0.073 & 0.178 \\
\hline 9 & 0.034 & 0.101 & 0.018 & 0.07 & 0.100 \\
\hline 12 & 0.011 & 0.085 & 0.015 & 0.126 & 0.083 \\
\hline 15 & 0.006 & 0.044 & 0.019 & 0.03 & 0.019 \\
\hline 18 & 0.003 & 0.0035 & 0.095 & 0.053 & 0.047 \\
\hline 21 & 0.0018 & 0.0035 & 0.115 & 0.077 & 0.020 \\
\hline 24 & 0.0020 & 0.0694 & 0.099 & 0.06 & 0.029 \\
\hline 27 & 0.02 & 0.0477 & 0.0136 & 0.014 & -0.014 \\
\hline 30 & 0.09 & 0 & -0.007 & 0 & -0.04 \\
\hline
\end{tabular}

In the Tubular-B, NPE was lower than $1 \mathrm{~g}^{-1}$ until day 15 ; then it increased, with a maximum value of 0.188 $\mathrm{g}^{-1}$ (Fig. 6).

In contrast, the Twin Layer-S, showed higher values of NPE during the first nine days of the experiment, resulting in a maximum of $0.208 \mathrm{~g}^{-1}$ on day 6 ; then the value decreased to about $0.1 \mathrm{~g}^{-1}$ (Fig. 6).

\section{Discussion}

For the experiment, a light intensity of $100 \mu \mathrm{mol}$ photons $\mathrm{m}^{-2} \mathrm{~s}^{-1}$ was chosen because G. sulphuraria generally grows at low light intensities in the natural environment (Pinto et al. 2007; Eren et al. 2018) and also showed promising results in both liquid and immobilized cultivation systems with respect to its 

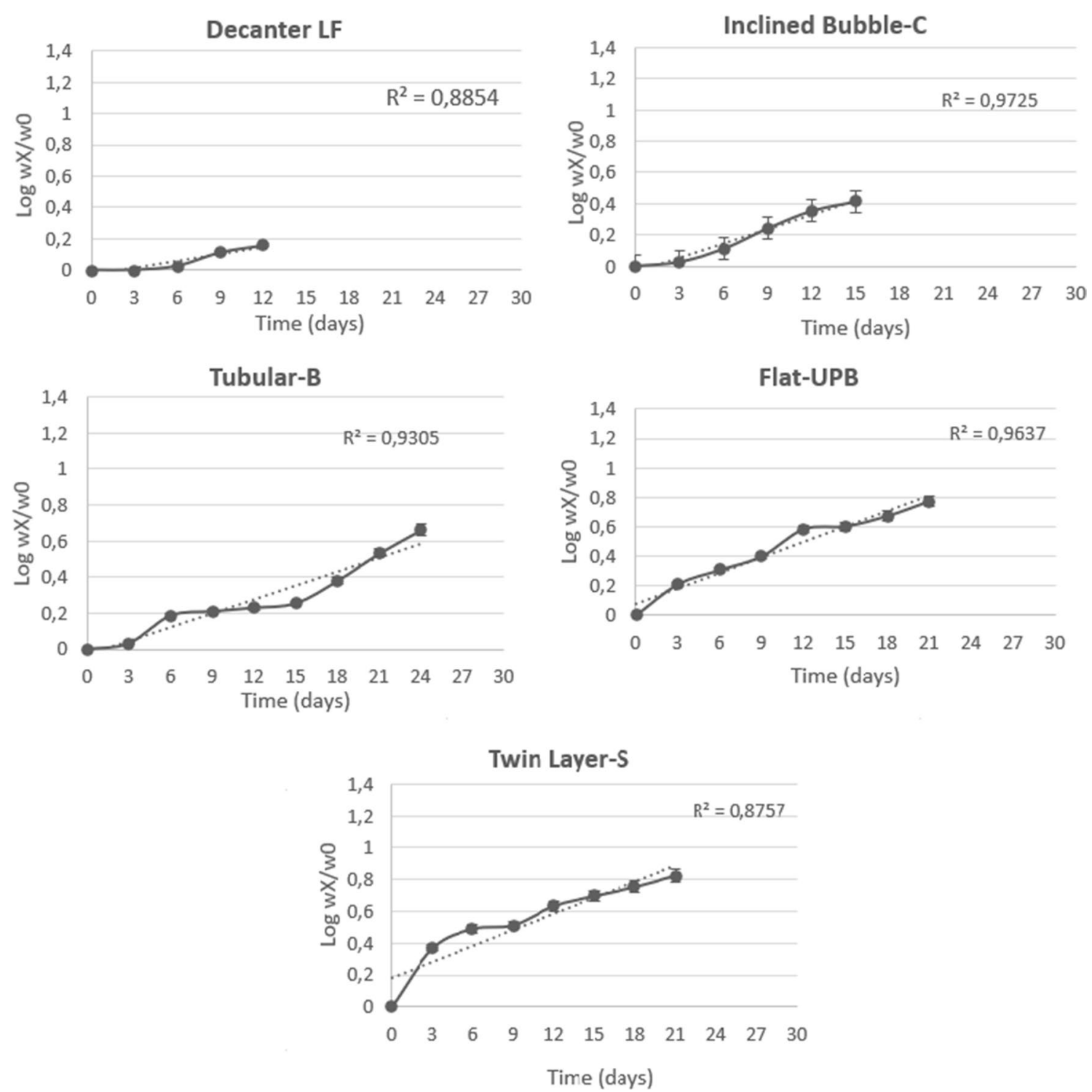

Fig. 3 Biomass trends and equation of the line and $R^{2}$ values in the different systems

physiology and in relation to applications in biotechnology (e.g. Sano et al. 2001; Oesterhelt et al. 2007; Carbone et al. 2020). For the latter, exposition at this light intensity leads to an increase of phycobiliprotein production: Carbone et al. (2020) e.g. showed, in an experiment with a Twin Layer-S using different light intensities that $100 \mu \mathrm{mol}$ photons $\mathrm{m}^{-2} \mathrm{~s}^{-1}$ was the optimal light intensity for production of phycobiliproteins, also Hirooka and Miyagishima (2016) obtained good production of phycocyanin at this light intensity in a suspended cultivation system using hot spring water supplemented with $\mathrm{NH}_{4}{ }^{+}$as culture medium.
By comparing growth, productivity and photosyntesis performances, the Decanter LF showed the lowest level of biomass growth and photosynthetic performance, despite it is the most common system used for G. sulphuraria growth (Iovinella et al. 2018; Carfagna et al. 2018) it. Indeed, it was placed on a plate shaker; the absence of bubbling didn't allow a good mixing of the culture for gas exchange, although the Decanter ensures a good mixing of nutrients around each cell surface (Rodriguez-Maroto et al. 2005; Mata et al. 2010).

In literature, better performances are commonly reported for microalgae in the Inclined Bubble- $\mathrm{C}$ and 
a $\rightarrow$-Flat-UPB $\multimap$ Inclined Bubble-C $\rightarrow$ Decanter-LF $\rightarrow$ Tubular-B $\longrightarrow$ Twin Layer-S

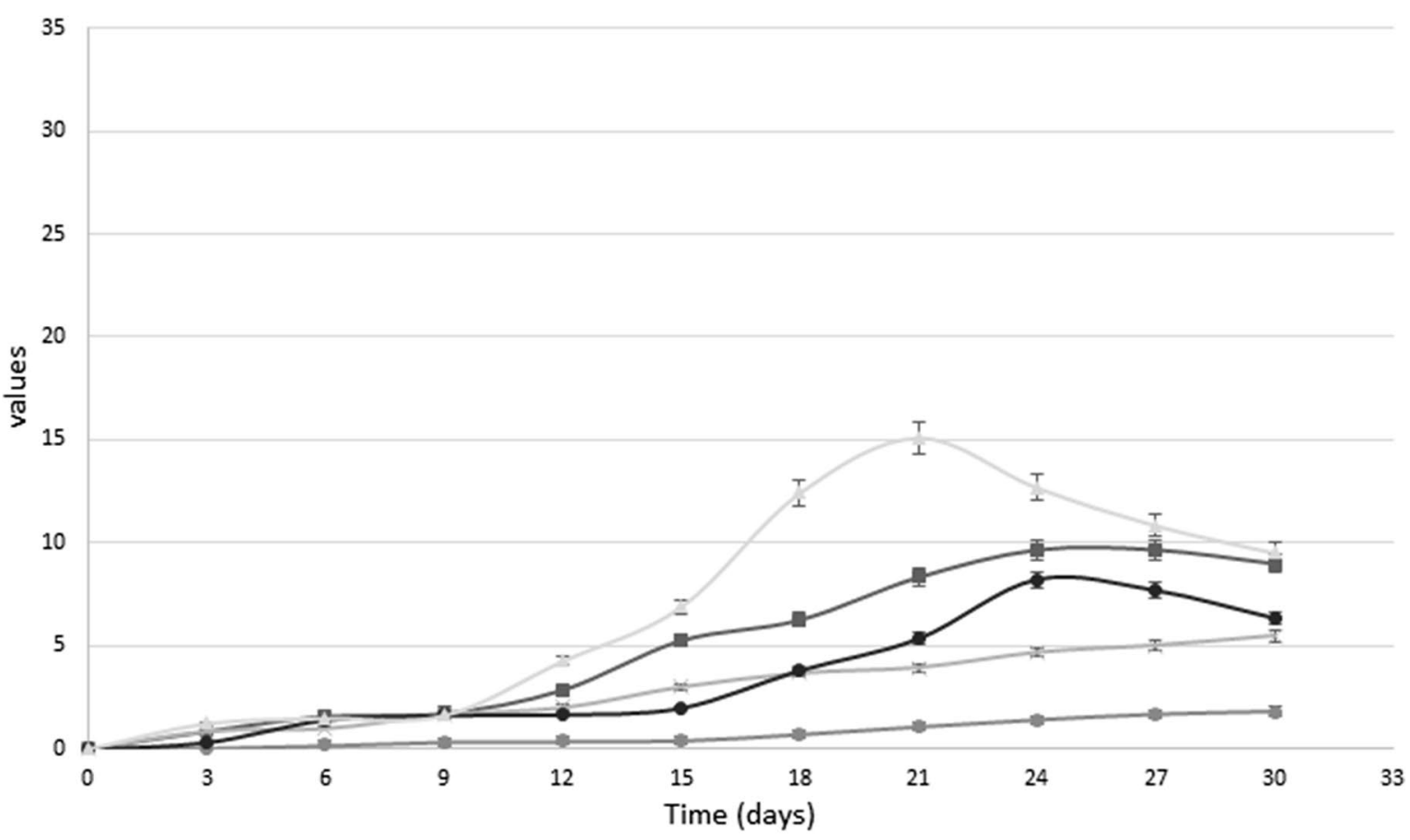

b

SP(X) Carotenoids

$\rightarrow$ Flat-UPB $\longrightarrow$ Inclined Bubble-C $\rightarrow$ Decanter-LF $\rightarrow$ Tubular-B $\longrightarrow$ Twin Layer-S

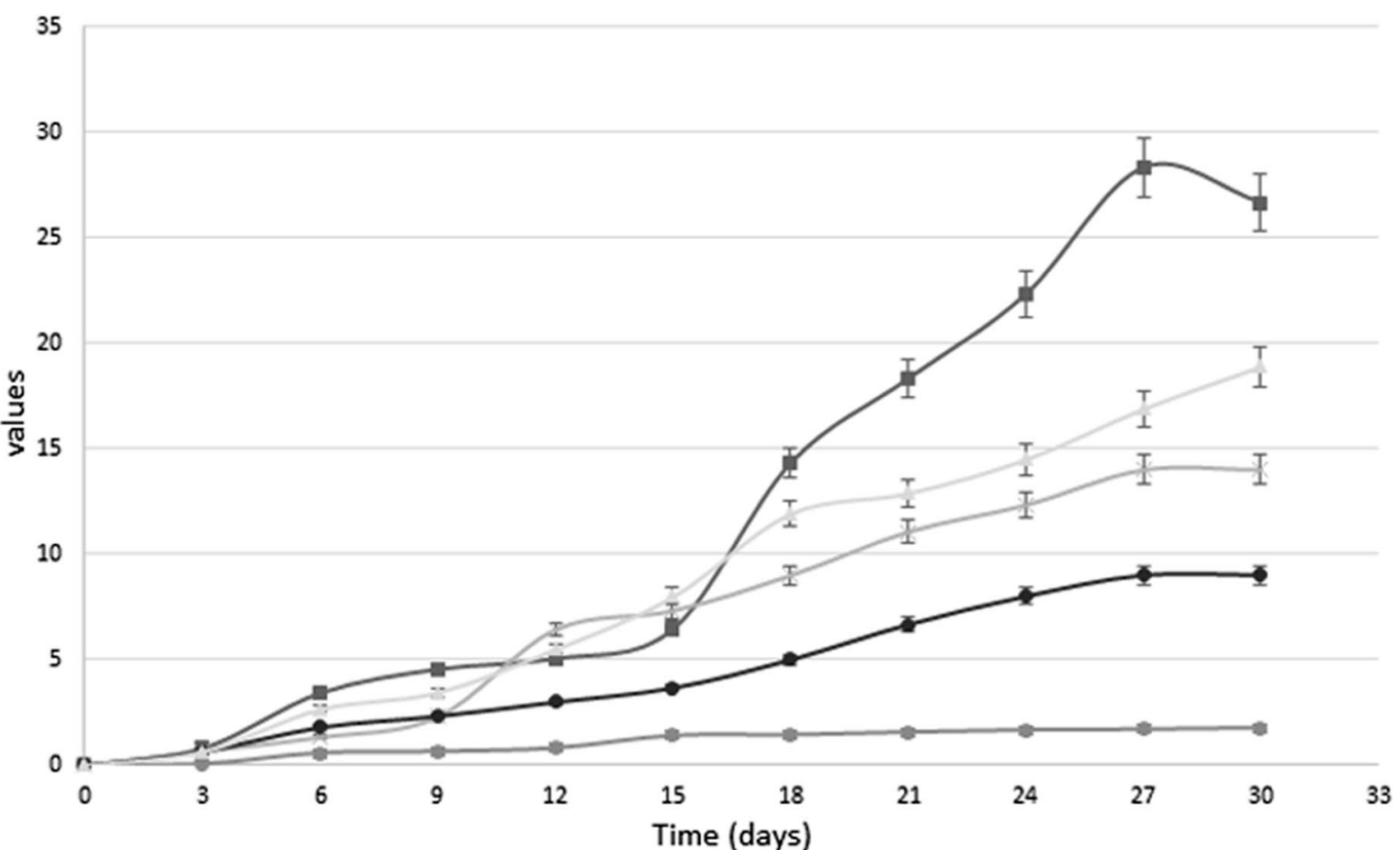

Fig. 4 a Specific chlorophyll a increase in different systems during the course of experiment. b Specific total carotenoids increase in different systems during the course of experiment 
Table 2 Specific increase of pigments in different systems

\begin{tabular}{|c|c|c|c|c|c|}
\hline DAYS & $\begin{array}{l}\text { Decanter laboratory flask } \\
\text { (DLF) }\end{array}$ & $\begin{array}{l}\text { Inclined bubble column } \\
\text { (IB-C) }\end{array}$ & $\begin{array}{l}\text { Tubular bioreactor } \\
\text { (T-B) }\end{array}$ & $\begin{array}{l}\text { Ultra-flat plate bioreactor } \\
\text { (UP-B) }\end{array}$ & $\begin{array}{l}\text { Twin layer } \\
\text { system } \\
\text { (TW-S) }\end{array}$ \\
\hline \multicolumn{6}{|c|}{ Specific pigment increase (SP) chlorophyll a } \\
\hline 0 & 0 & 0 & 0 & 0 & 0 \\
\hline 3 & 0.04 & 0.86 & 0.32 & 0.86 & 1.2 \\
\hline 6 & 0.16 & 1 & 1.4 & 1.6 & 1.49 \\
\hline 9 & 0.33 & 1.66 & 1.62 & 1.73 & 1.62 \\
\hline 12 & 0.36 & 2 & 1.66 & 2.86 & 4.26 \\
\hline 15 & 0.4 & 3 & 1.98 & 5.26 & 6.89 \\
\hline 18 & 0.7 & 3.66 & 3.8 & 6.26 & 12.4 \\
\hline 21 & 1.06 & 3.9 & 5.3 & 8.2 & 15.1 \\
\hline 24 & 1.4 & 4.66 & 8.2 & 9.6 & 12.68 \\
\hline 27 & 1.66 & 5 & 7.6 & 9.6 & 10.8 \\
\hline 30 & 1.8 & 5.4 & 6.3 & 9 & 9.5 \\
\hline \multicolumn{6}{|c|}{ Specific pigment increase (SP) carotenoids } \\
\hline 0 & 0 & 0 & 0 & 0 & 0.64 \\
\hline 3 & 0.033 & 0.66 & 0.66 & 0.81 & 2.65 \\
\hline 6 & 0.56 & 1.3 & 1.8 & 3.43 & 3.45 \\
\hline 9 & 0.63 & 2.3 & 2.3 & 4.5 & 5.49 \\
\hline 12 & 0.8 & 6.4 & 3 & 5 & 7.98 \\
\hline 15 & 1.4 & 7.3 & 3.6 & 6.4 & 11.92 \\
\hline 18 & 1.43 & 9 & 5 & 14.4 & 12.3 \\
\hline 21 & 1.56 & 11 & 6.6 & 18.3 & 14.23 \\
\hline 24 & 1.66 & 12.3 & 8 & 22.33 & 16.2 \\
\hline 27 & 1.7 & 15 & 9 & 28.3 & 18.9 \\
\hline 30 & 1.76 & 14 & 9 & 26.6 & 18.8 \\
\hline
\end{tabular}

the Flat-UPB than in the Tubular-B. For example, Olivieri et al. (2011) showed that the green alga Stichococcus bacillaris grows better in the Inclined Bubble-C than in the Tubular-B; and De Vree et al. (2015) reported that Nannochloropsis sp. achieved higher biomass concentrations and enhanced photosynthesis performance in a flat panel cultivation system very similar to the Flat-UPB compared to other cultivation systems including a Tubular-B. Also, a number of studies found very high biomass levels were obtained with different microalgal genera such as Nannochloropsis, Chlorococcum, Scenedesmus and Arthrospira in a Flat UPB (Zhang et al. 2002; Koller et al. 2018; Hu et al. 1998; De Vree et al. 2015; Safafar et al. 2016; Tredici and Zitelli 1997).

In our experiments, G. sulphuraria had better performances in the Tubular-B among the suspended cultivation systems tested; these differences are probably linked to the particular physiology of this microalga. Indeed, $G$. sulphuraria is an extremophile organism that can survive in the dark up to five months (Gross et al. 1998) achieving very high biomass densities under heterotrophic conditions (Gross and Schnarrenberger 1995; Graverholt and
Eriksen 2007; Eriksen 2018; Sloth et al. 2006). Generally, heterotrophy is not typical for red algae, and presumably, this is a strategy of G.sulphuraria to survive in extreme environments (Gross et al. 1998; Gaignard et al. 2019).

Therefore, the high illumination area of the Flat-UPB and high radial macroscopic circulation of the Inclined Bubble-C represent a drawback for an organism that lives in a cryptoendolithic condition, under which light is scarce or absent for days (Thangaraj et al. 2011; Gross et al. 1998; Janssen et al. 2003).

The Tubular- $\mathrm{B}$ has a low radial macroscopic circulation that causes a shadow effect, due to external microalgal biomass that capture most of the incident light, thus creating a low-light environment for inner cells of the suspension (González-Camejo et al. 2019; Hu et al. 1998; Kiperstok et al. 2017; Zuccaro et al. 2020; Carbone et al. 2019). In this way a condition similar to the endolithic state is generated.

Whereas the Inclined Bubble- $\mathrm{C}$ displayed lower growth and photosynthetic performance than the Tubular-B, the Flat-UPB had similar growth performance but lower photosynthetic activity than the Tubular-B. 


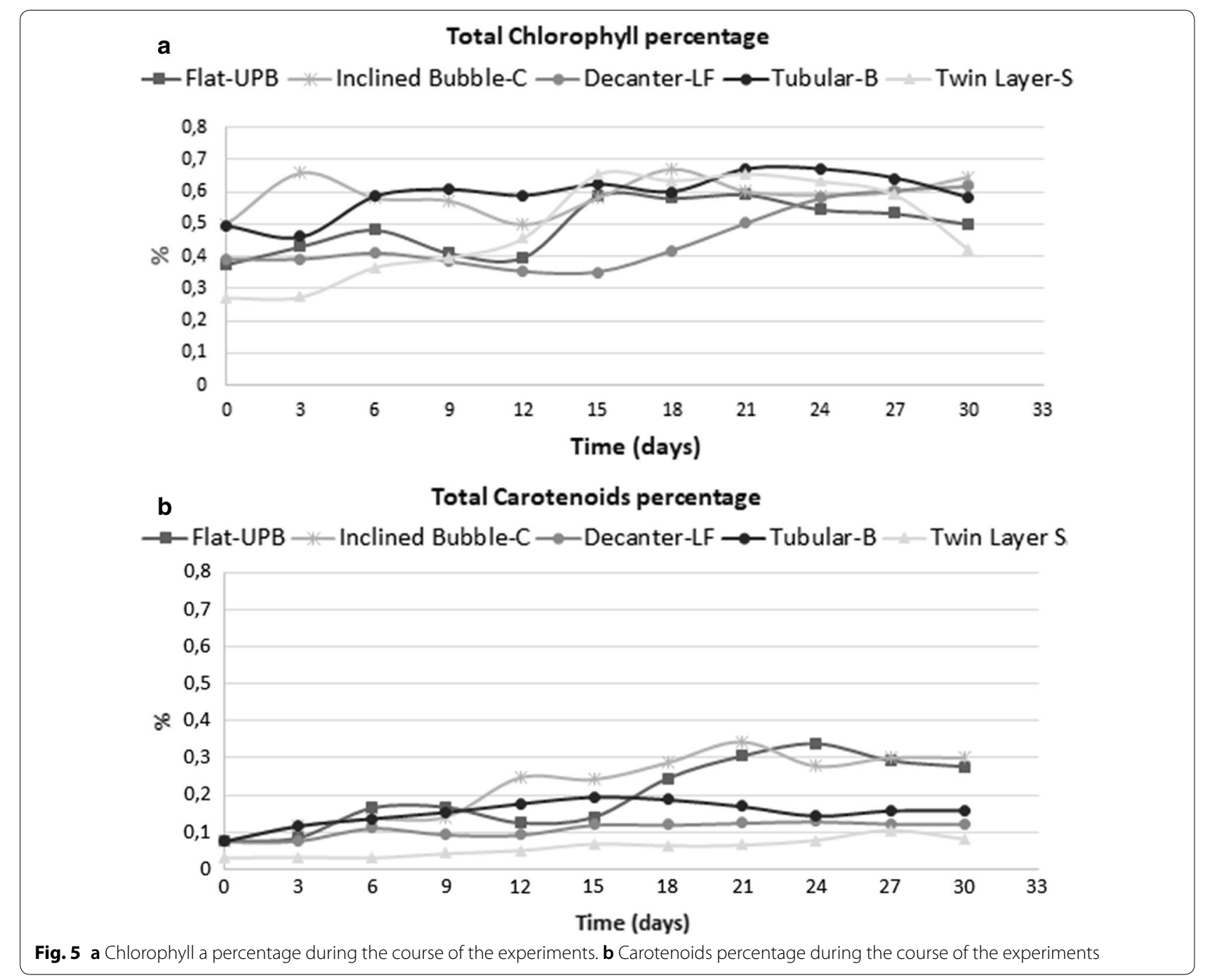

The Tubular-B and the Flat-UPB had high chlorophyll contents, and as reported in the literature, this is directly connected to the photochemical performance of PSII, and, as a consequence, of photosynthetic activity and indirectly also to growth performance (Schreiber et al. 1998; Zuccaro et al. 2019).

However, algae grown in the Flat-UPB revealed higher percentage levels of carotenoids compared to those grown in the Tubular-B, indicating a stressful condition of the alga. Indeed, carotenoids perform an essential photoprotective role by quenching the triplet state chlorophyll molecules, scavenging toxic oxygen species formed during light stress, dissipating harmful excess excitation energy under light stress (Pisal and Lele 2005; Galasso et al. 2017; Takaichi 2011; González-Fernández et al. 2012; Sosa-Hernández et al. 2019; Sun et al. 2016).

Moreover, despite the good growth performance of the Flat UPB, the productivity is lower than that in the
Tubular-B. Indeed, normalized photosynthesis performance is lower in the Flat-UPB.

Although the Tubular-B seems to be the best of the different suspended cultivation systems tested, the results obtained in this system are not comparable with the Twin Layer-S, in which G. sulphuraria exhibited best growth, photosynthetic performance and productivity. This result is not surprising: in natural environments, these microalgae generally live attached to substrates like soil or rocks and the Twin Layer-S partly reproduces conditions similar to the natural habitat of this species (Li et al. 2017; Melkonian and Podola 2010; Moreno Osorio 2018).

Moreover, in the Twin Layer-S the lower cell layers of the biofilm are permanently shaded by the upper cell layers due to immobilization of the cells, thus minimizing photoinhbition (Gross et al. 1998; Schultze et al. 2015; Piltz and Melkonian 2018; Langenbach and Melkonian 2019; Kim et al. 2019). In consequence, 


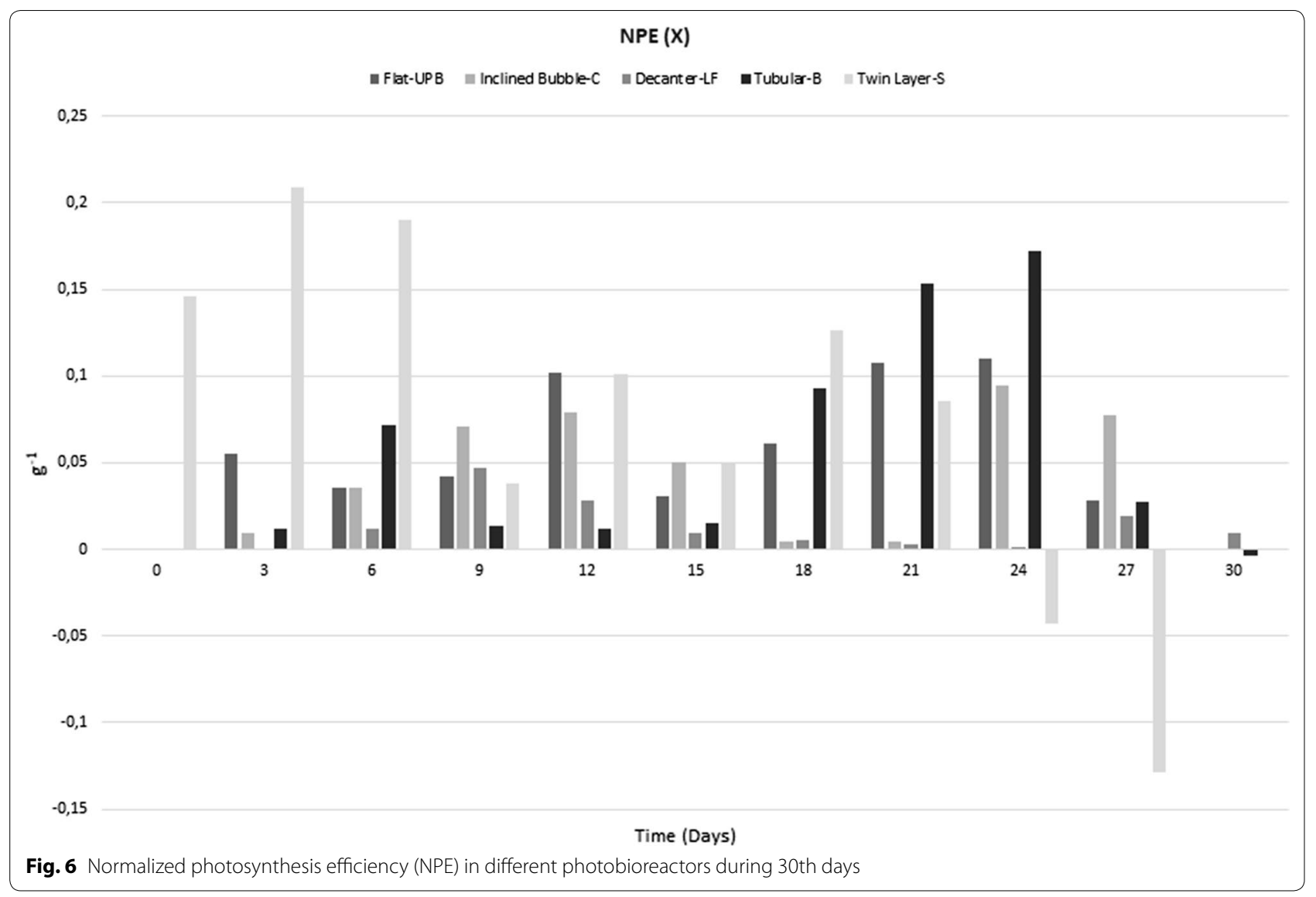

G. sulphuraria achieves high growth and photosynthetic performance also at light intensities that inhibit growth and photosynthetic performance in suspended cultures, such as $200 \mu \mathrm{mol}$ photons $\mathrm{m}^{-2} \mathrm{~s}^{-1}$ (Carbone et al. 2020).

Eventually, Twin Layer-S offers also some economics advantages for mass cultures of G. sulphuraria (Carbone et al. 2017a; Podola et al. 2017; Pierobon et al. 2018; Zhuang et al. 2018). Many high costs linked to suspended cultivation systems are eliminated: for example, the biomass is harvested directly by scraping, without a preconcentration step; there are lower water consumption and space utilization. Furthermore, the system is modular, thus easily scalable. However, in comparison with submerged photobioreactor, which have been sufficiently tested and analysed also at pilot and industrial scale, the Twin-layer-S has still to be completely validated at a relevant and demonstrative scale. Thus, while technoeconomic analysis of closed photobioreactor are already available in literature, an representative and meaningfull economic analysis of the Twin-layer-S has still to be performed.

\section{Acknowledgements}

Not applicable.

\section{Authors' contributions}

DC performed experiments and wrote the draft manuscript, GO worked on the mathematical formulae, AP provided laboratory space and facilities, and MM conceived the project and revised the draft manuscript. All authors read and approved the final manuscript.

\section{Funding}

Not applicable.

\section{Availability of data and materials \\ All data and materials are available.}

\section{Ethics approval and consent to participate}

This article does not contain any studies with human participants and animals performed by any of the authors.

\section{Consent for publication}

All authors consent the publication.

\section{Competing interests}

The authors declare that they have no conflict of interest.

\section{Author details}

'Laboratory of Biological Oceanography, Stazione Zoologica "A. Dohrn" of Napoli, Villa Comunale, Napoli I80121, Italy. ${ }^{2}$ Bioprocess Engineering, AlgaePARC, Wageningen University and Research, PO Box 16, 6700 AA Wageningen, The Netherlands. ${ }^{3}$ Dipartimento di Ingegneria Chimica, dei Materiali e della Produzione Industriale, Università degli Studi di Napoli Federico II, Piazzale Vincenzo Tecchio, 80, 80125 Napoli, Italia. ${ }^{4}$ Dipartimento di Biologia, Università degli Studi di Napoli Federico II, Via Cinthia, 26, 80126 Napoli, Italia. ${ }^{5}$ Institut für Pflanzenwissenschaften, Universität zu Köln, Zülpicher Str. 47b, 
50674 Cologne, Germany. ${ }^{6}$ Present Address: Max Planck Institute for Plant Breeding Research, Carl-von-Linne-Weg 10, 50829 Cologne, Germany.

Received: 2 September 2020 Accepted: 9 September 2020 Published online: 21 September 2020

\section{References}

Albertano P, Ciniglia C, Pinto G, Pollio A (2000) The taxonomic position of Cyanidium, Cyanidioschyzon and Galdieria: an update. Hydrobiologia 433:137-143

Alalwan HA, Alminshid AH, Aljaafari HAS (2019) Promising evolution of biofuel generations. Subject Review. Renew Energy Focus 28:127-139

Aslanbay Guler B, Deniz I, Demirel Z, Oncel SS, Imamoglu E (2019) Comparison of different photobioreactor configurations and empirical computational fluid dynamics simulation for fucoxanthin production. Algal Res 37:195-204

Carbone DA, Olivieri G, Pollio A, Pinto G, Melkonian M (2017a) Growth and biomass productivity of Scenedesmus vacuolatus on a twin layer system and a comparison with other types of cultivations. Appl Microbiol Biotechnol 101:8321-8329

Carbone DA, Gargano I, Pinto G, De Natale A, Pollio A (2017b) Evaluating microalgal attachment to surfaces: a first approach towards a laboratory integrated assessment. Chem Eng Trans 57:73-78

Carbone DA, Olivieri G, Pollio A, Melkonian M (2020) Biomass and phycobiliprotein production of Galdieria sulphuraria immobilized on a twin-layer porous substrate photobioreactor. Appl Microbiol Biotechnol 104:3109-3119

Carbone DA, Gargano I, Chiaiese P, Pollio A, Marotta R, Olivieri G, Pinto G (2018) Scenedesmus vacuolatus cultures for possible combined laccase-like phenoloxidase activity and biodiesel production. Ann Microbiol 68:9-15

Carbone DA, Gargano I, Olivieri G, Marzocchella A, Andreozzi R, Marotta R, Spasiano D, Pinto G, Pollio A (2019) Light intensities maximizing photosynthesis and kinetics of photochemical steps in Graesiella emersonii under different cultivation strategies. Environ Engergy Manag J 18:1527-1534

Carfagna S, Salbitani G, Bottone C, Vona V (2016) Galdieria sulphuraria as a possible source of food colorant. J Nutr Ecol Food Res 3:78-81

Carfagna S, Landi V, Coraggio F, Salbitani G, Vona V, Pinto G, Pollio A, Ciniglia C (2018) Different characteristics of C-phycocyanin (C-PC) in two strains of the extremophilic Galdieria phlegraea. Algal Res 31:46-52

Castenholz RW, McDermott TR (2010) The Cyanidiales: ecology, biodiversity, and biogeography. In: Seckbach J, Chapman DJ (eds) Red algae in the genomic age. Springer, Dordrecht, pp 357-371

Ciniglia C, Yoon HS, Pollio A, Pinto G, Bhattacharya D (2004) Hidden biodiversity of the extremophilic Cyanidiales red algae. Mol Ecol 13:1827-1838

Ciniglia C, Yang EC, Pinto G, lovinella M, Vitale L, Yoon HS (2014) Cyanidiophyceae in Iceland: plastid rbcL gene elucidates origin and dispersal of extremophilic Galdieria sulphuraria and Galdieria maxima (Galdieriaceae, Rhodophyta). Phycologia 53:542-551

Ciniglia C, lovinella M, Olivieri G, Cennamo P, Pollio A (2017) A potential use of the polyextremophilic microalga Galdieria sulphuraria (Cyanidiophyceae, Rodhophyta) in bio-recovery of rare metals. Phycologia Suppl 56:33-35

Costache M, Campeanu G, Neata G (2012) Studies concerning the extraction of chlorophyll and total carotenoids from vegetables. Roman Biotechnol Lett 17:7702-7708

da Silva VB, Moreira JB, de Morais MG, Costa JAV (2016) Microalgae as a new source of bioactive compounds in food supplements. Curr Opin Food Sci 7:73-77

Delia L, De Mondo A, Santoro M, De Natale A, Pinto G, Pollio A (2018) Microorganism from harsh and extreme environments: a collection of living strains at ACUF (Naples Italy). Ecol Qual 29:3-4

Del Mondo A, lovinella M, Petriccione A, Seth D, Cioppa D, Ciniglia C (2019) A spotlight on Rad52 in Cyanidiophytina (Rhodophyta): a relic in algal heritage. Plants 8:46

De Vree JH, Bosma R, Janssen M, Barbosa MJ, Wijffels RH (2015) Comparison of four outdoor pilot-scale photobioreactors. Biotechnol Biofuels 8:215

Dupré C, Burrows HD, Campos MG, Delattre C, Encarnação T, Fauchon M, Gaignard C, Hellio C, Ito J, Laroche J, Legrand J, Michaud P, Pais A, Pierre G, Benoit S, Watanabe MM (2020) Microalgal biomass of industrial interest: methods of characterization. In: Nzihou A (ed) Handbook on characterization of biomass, biowaste and related by-products. ChamSpringer International Publishing, Springer, pp 537-639

Eren A, lovinella M, Yoon HS, Cennamo P, de Stefano M, de Castro O, Ciniglia C (2018) Genetic structure of Galdieria populations from Iceland. Polar Biol 41:1681-1691

Eriksen NT (2018) Heterotrophic production of phycocyanin in Galdieria sulphuraria. In: Durvasula RV, Subba Rao DV (eds) Extremophiles-from biology to biotechnology. CRC Press, Boca Raton, pp 87-101

Gaignard C, Gargouch N, Dubessay P, Delattre C, Pierre G, Laroche C, Fendri I, Abdelkafi S, Michaud P (2019) New horizons in culture and valorisation of red microalgae. Biotechnol Adv 37:193-222

Galasso C, Corinaldesi C, Sansone C (2017) Carotenoids from marine organisms: biological functions and industrial applications. Antioxidants 6:96-100

Galasso C, Gentile A, Orefice I, lanora I, Bruno A, Noonan DM, Sansone C, Albini A, Brunet C (2019) Microalgal derivatives as potential nutraceutical and food supplements for human health: a focus on cancer prevention and interception. Nutrients 11:1226-1230

Gifuni I, Olivieri G, Pollio A, Marzocchella A (2018) New ultra-flat photobioreactor for intensive microalgal production: the effect of light irradiance. Algal Res 34:134-142

González-Fernández C, Sialve B, Bernet N, Steyer JP (2012) Impact of microalgae characteristics on their conversion to biofuel. Part II: focus on biomethane production. Biofuels Bioprod Bioref 6:205-218

González-Camejo JA, Viruela MV, Ruano R, BaratA Seco J, Ferrer A (2019) Dataset to assess the shadow effect of an outdoor microalgae culture. Data in Brief 25:25-35

Graverholt OS, Eriksen NT (2007) Heterotrophic high cell-density fed-batch and continuous flow cultures of Galdieria sulphuraria and production of phycocyanin. Appl Microbiol Biotechnol 77:69-75

Graziani G, Schiavo S, Nicolai MA, Buono S, Fogliano V, Pinto G, Pollio A (2013) Microalgae as human food: chemical and nutritional characteristics of the thermo-acidophilic microalga Galdieria sulphuraria. Food Funct 4:144-152

Gross W (2000) Ecophysiology of algae living in highly acidic environments. Hydrobiol 33:31-37

Gross W, Schnarrenberger C (1995) Heterotrophic growth of two strains of the acid-thermophilic red alga Galdieria sulphuraria. Plant Cell Physiol 36:4-9

Gross W, Kuver J, Tischendorf G, Bouchaala N, Busch W (1998) Cryptoendolithic growth of the red alga Galdieria sulphuraria in volcanic areas. Eur J Phycol 33:25-31

Heilmann I, Gross W (2001) Genetic diversity of thermo-acidophilic red algae according to random amplified polymorphic DNA (RAPD) analysis. Nova Hedw Beih 123:531-539

Henkanette-Gedera ST, Selvaratnam M, Karbakhshravari M, Myint N, Nirmalakhandan W, Van Voorhies D, Lammer PJ (2016) Removal of dissolver organic carbon and nutrients from urban wastewater by Galdieria sulphuraria: laboratory to field scale demonstration. Algal Res 24:450-456

Hirooka S, Miyagishima SY (2016) Cultivation of acidophilic algae Galdieria sulphuraria and Pseudochlorella sp. YKT1 in media derived from acidic hot springs. Front Microbiol 7:20-22

Hu Q, Kurano N, Kawachi M, Iwasaki I, Miyachi S (1998) Ultrahigh-cell-density culture of a marine green alga Chlorococcum littorale in a flat-plate photobioreactor. Appl Microbiol Biotechnol 49:655-662

lovinella M, Eren A, Pinto G, Pollio A, Davis SJ, Cennamo P, Ciniglia C (2018) Cryptic dispersal in non-acidic environments from Turkey of Cyanidiophytina (Rhodophyta). Extremophiles 22:713-723

lovinella M, Carbone DA, Cioppa D, Davis SJ, Innangi M, Esposito S, Ciniglia C (2020) Prevalent pH controls the capacity of Galdieria maxima to use ammonia and nitrate as a nitrogen source. Plants 9:232

Janssen M, Tramper J, Mur LR, Wijffels RH (2003) Enclosed outdoor photobioreactors: light regime, photosynthetic efficiency, scale-up, and future prospects. Biotechnol Bioeng 81:193-210

Ju X, Igarashi K, Miyashita K, Mitsuhashi H, Inagaki K, Fujii S, Sawada H, Kuwabara T, Minoda A (2016) Effective and selective recovery of gold and palladium ions from metal wastewater using a sulphothermophilic red alga, Galdieria sulphuraria. Bioresour Technol 211:759-764

Kim S, Moon M, Kwak M, Lee B, Chang YK (2019) Statistical optimization of light intensity and $\mathrm{CO} 2$ concentration for lipid production derived from attached cultivation of green microalga Ettlia sp. Sci Rep 8:153-190 
Kiperstok AC, Sebestyén P, Podola B, Melkonian M (2017) Biofilm cultivation of Haematococcus pluvialis enables a highly productive one-phase process for astaxanthin production using high light intensities. Algal Res 21:213-222

Koller AP, Wolf L, Bruck T, Weuster Botz D (2018) Studies on the scale-up of biomass production with Scenedesmus spp. in flat-plate gas-lift photobioreactors. Bioproc Biosyst Eng 41:213-220

Langenbach D, Melkonian M (2019) Optimising biomass and peridinin accumulation in the dinoflagellate Symbiodinium voratum using a twin-layer porous substrate bioreactor. J Appl Phycol 31:21-28

Li T, Strous M, Melkonian M (2017) Biofilm-based photobioreactors: their design and improving productivity through efficient supply of dissolved inorganic carbon. FEMS Microbiol Lett 5:364-365

Mata TM, Martins AA, Caetano NS (2010) Microalgae for biodiesel production and other applications: a review. Renew Sustain Energy Rev 14:217-232

Melkonian M, Podola B (2010) Method and device for cultivating eukaryotic microorganisms or blue algae, and biosensor with cultivated eukaryotic microorganisms or blue algae. United States Patent No US 7(745):20

Minoda A, Sawada H, Suzuki S, Miyashita S, Inagaki K, Yamamoto T, Tsuzuki M (2015) Recovery of rare earth elements from the sulfo-thermophilic red alga Galdieria sulphuraria using aqueous acid. Appl Microbiol Biotechnol 99:1513-1519

Moreno Osorio JH, Luongo V, Del Mondo A, Pinto G, Frunzo L, Lens PNL, Esposito G (2018) Nutrient removal from high strength nitrate containing industrial wastewater using Chlorella sp. strain ACUF_802. Ann Microbiol 68:899-913

Nowack ECM, Podola B, Melkonian M (2005) The 96-well twin-layer system: a novel approach in the cultivation of microalgae. Protist 156:239-251

Oesterhelt C, Schmalzlin E, Schmitt JM, Lokstein H (2007) Regulation of photosynthesis in the unicellular acidophilic red alga Galdieria sulphuraria. Plant J 51:500-511

Olivieri G, Marzocchella A, Andreozzi R, Pinto G, Pollio A (2011) A biodiesel production from Stichococcus strains at laboratory scale. J Chem Technol Biotechnol 20:776-783

Olivieri G, Gargano I, Andreozzi R, Marzocchella A, Pinto G, Polio A (2012) Effects of photobioreactors design and operating conditions on Stichococcus bacillaris biomass and biodiesel production. Biochem Eng J 74:8-14

Pierobon SC, Cheng X, Graham PJ, Nguyen B, Karakolis EG, Sinton D (2018) Emerging microalgae technology: a review. Sustain Energy Fuels 2:13-38

Piltz B, Melkonian M (2018) Immobilized microalgae for nutrient recovery from source-separated human urine. J Appl Phycol 30:421-429

Pinto G, Albertano P, Ciniglia C, Cozzolino S, Pollio A, Yoon HS, Bhattacharya D (2003) Comparative approaches to the taxonomy of the genus Galdieria merola (Cyanidiales, Rhodophyta). Crypt Algol 24:13-32

Pinto G, Ciniglia C, Cascone C, Pollio A (2007) Species composition of Cyanidiales assemblages in Pisciarelli (Campi Flegrei, Italy) and description of Galdieria phlegrea sp. nov. In: Seckbach J (ed) Algae and cyanobacteria in extreme environments. Springer, Dordrecht, pp 487-502

Pisal DS, Lele SS (2005) Carotenoid production from microalgae, Dunaliella salina. Indian J Biotechnol 4:476-483

Podola B, Li T, Melkonian M (2017) Porous substrate bioreactors: a paradigm shift in microalgal biotechnology? Trends Biotechnol 35:121-132

Rodriguez-Maroto JM, Jimenez C, Aguilera J, Niell FX (2005) Air bubbling results in carbon loss during microalgal cultivation in bicarbonateenriched media: experimental data and process modeling. Aquacult Eng 32:493-508

Sano S, Ueda M, Kitajima S, Takeda T, Shigeoka S, Kurano N, Miyachi S, Miyake C, Yokota A (2001) Characterization of ascorbate peroxidases from unicellular red alga Galdieria partita. Plant Cell Physiol 42:433-440

Safafar H, Hass M, Møller P, Holdt SL, Jacobsen C (2016) High-EPA biomass from 473 Nannochloropsis salina cultivated in a flat-panel photo-bioreactor on a process water-enriched 474 growth medium. Mar Drugs 14:1-19

Schmidt RA, Wiebe MG, Eriksen NT (2005) Heterotrophic high cell-density fed-batch cultures of the phycocyanin producing red alga Galdieria sulphuraria. Biotechnol Bioeng 90:77-84
Schreiber U, Bilger W, Hormann H, Neubauer C (1998) Chlorophyll fluorescence as a diagnostic tool: basics and some aspects of practical relevance. In: Raghavendra AS (ed) Photosynthesis: a comprehensive treatise. Cambridge University Press, Cambridge, pp 320-336

Schultze LKP, Simon MV, Li T, Langenbach D, Podola B, Melkonian M (2015) High light and carbon dioxide optimize surface productivity in a twinlayer biofilm photobioreactor. Algal Res 8:37-44

Sloth JK, Wiebe MG, Eriksen NT (2006) Accumulation of phycocyanin in heterotrophic and mixotrophic cultures of the acidophilic red alga Galdieria sulphuraria. Enzym Microb Technol 38:168-175

Sørensen L, Hantke A, Eriksen NT (2013) Purification of the photosynthetic pigment C-phycocyanin from heterotrophic Galdieria sulphuraria. J Sci Food Agric 93:2933-2938

Sosa-Hernández JE, Romero-Castillo, KD, Parra-Arroyo L, Aguilar-Aguila-Isaías MA, García-Reyes IE, Ahmed, I, Parra-Saldivar R, Bilal M, labal H (2019) Mexican microalgae biodiversity and state-of-the-art extraction strategies to meet sustainable circular economy challenges: high-value compounds and their applied perspectives. Mar Drugs 17:174-178

Sun YH, Liao Q, Huang Y, Xia A, Fu Q, Zhu X, Zheng YP (2016) Integrating planar waveguides doped with light scattering nanoparticles into a flat-plate photobioreactor to improve light distribution and microalgae growth. Bioresour Technol 220:215-224

Takaichi S (2011) Carotenoids in algae: distributions, biosyntheses and functions. Mar Drugs 9:1101-1118

Thangaraj B, Jolley CC, Sarrou I, Bultema JB, Greyslak J, Whitelegge JP, Lin S, Kouril R, Subramanyam R, Boekema EJ (2011) Efficient light harvesting in a dark, hot, acidic environment: the structure and function of PSI-LHCl from Galdieria sulphuraria. Biophys J 100:135-143

Tomitani A, Okada K, Miyashita H, Matthijs HCP, Ohno T, Tanaka A (1999) Chlorophyll $b$ and phycobilins in the common ancestor of cyanobacteria and chloroplasts. Nature 400:150-162

Toplin JA, Norris TB, Lehr CR, McDermott TR, Castenholz RW (2008) Biogeographic and phylogenetic diversity of thermoacidophilic Cyanidiales in Yellowstone National Park, Japan and New Zealand. Appl Environ Microbiol 74:2822-2833

Tredici MR, Zitelli GC (1997) Cultivation of Spirulina (Arthrospira) platensis in flat plate reactors. In: Vonshak A (ed) Spirulina platensis (Arthrospira): physiology, cell biology and biotechnology. Taylor and Francis, London, pp 117-130

Vítová M, Goecke F, Sigler K, Řezanka T (2016) Lipidomic analysis of the extremophilic red alga Galdieria sulphuraria in response to changes in $\mathrm{pH}$. Algal Res. 13:218-226

Yoon HS, Hackett JD, Ciniglia C, Pinto G, Bhattacharya D (2004) A molecular timeline for the origin of photosynthetic eukaryotes. Mol Biol Evol 21:809-818

Zhang K, Kurano N, Miyachi S (2002) Optimized aeration by carbon dioxide gas for microalgal production and mass transfer characterization in a vertical flat-plate photobioreactor. Bioprocess Biosyst Eng 25:97-101

Zhuang L, Dawey Y, Zhang J, Fei L, Yin W, Tian Z, Guo H, Hong Y (2018) The characteristic and influencing factor of microalga cultivation: a review. Renew Sustain Energy Rev 94:1110-1119

Zuccaro G, Steyer JP, Van Lis R (2019) The alga trophic mode effect interaction and oil production of a synergic microalga-yeast consortium. Biores Technol 237:608-617

Zuccaro G, Yousef A, Pollio A, Steyer JP (2020) Microalgae cultivation systems. In: Yousuf A (ed) Microalgae cultivation for biofuels production. Academic Press, New York, pp 11-29

\section{Publisher's Note}

Springer Nature remains neutral with regard to jurisdictional claims in published maps and institutional affiliations. 